\title{
Kant and the Pre-Conceptual Use of the Understanding
}

\author{
(pre-publication version, forthcoming in Archiv für Geschichte der Philosophie) \\ Jonas Jervell Indregard
}

\begin{abstract}
Does Kant hold that we can have intuitions independently of concepts? A striking passage from $\S 13$ of the Critique of Pure Reason appears to say so explicitly. However, it also conjures up a scenario where the categories are inapplicable to objects of intuition, a scenario presumably shown impossible by the following Transcendental Deduction. The seemingly non-conceptualist claim concerning intuition have therefore been read, by conceptualist interpreters of Kant, as similarly counterpossible. I argue that the passage in question best supports an underappreciated middle position where intuition requires a pre-conceptual use of the understanding. Such preconceptual use of the understanding faces both textual and systematic objections. I show that these objections can be rebutted.
\end{abstract}

Keywords: Kant, conceptualism, Transcendental Deduction, intuition, self-affection, synthesis

\section{Introduction}

Much interpretative effort has recently gone into determining whether Kant held that concepts are required for having intuitions, i.e., whether he was a conceptualist about intuition. ${ }^{1}$ A striking passage in $\S 13$ of $K r V$, the introduction to the Transcendental Deduction of the Categories (TD), has lent support to non-conceptualist interpretations: The conclusion of the passage states that "intuition by no means requires the functions of thinking" (A91/B123). ${ }^{2}$ Since concepts and

\footnotetext{
${ }^{1}$ While this is still the standard way of framing the question, when it comes to Kant it is arguably more appropriate to ask whether having intuitions depends on a contribution by the understanding. See McLear (2015, 2016); Gomes (2017). I return to this issue further below.

${ }^{2}$ References to Kant's works give Kant (1900-) volume and page, except the Kritik der reinen Vernunft where I use the standard A/B edition pagination. Translations are from Kant (1992-) or, where unavailable, my own. Abbreviations: Anth = Anthropologie in pragmatischer Hinsicht; Br = Briefe; EE = Erste Einleitung in die ,Kritik der Urteilskraft $; F M=$ Preisschrift über die Fortschritte der Metaphysik; GMS = Grundlegung zur Metaphysik der Sitten; ID = De mundi sensibilis atque intelligibilis forma et principiis; JL = Jäsche Logik; KrV = Kritik der reinen
} 
conceptual judgment involve "functions of thinking," this and other similar statements suggest that intuitions can be had prior to and independently of concepts.

Conceptualists respond by pointing to the context of the $\S 13$ passage: setting up the problem that TD is to resolve, namely demonstrating the objective validity of the categories. They argue that if the non-conceptualist is right about intuitions, this project is doomed to failure. As they point out, Kant himself sketches such prospects in the same $§ 13$ passage:

For appearances could after all be so constituted that the understanding would not find them in accord with the conditions of its unity, and everything would then lie in such confusion that, e.g., in the succession of appearances nothing would offer itself that would furnish a rule of synthesis and thus correspond to the concept of cause and effect, so that this concept would therefore be entirely empty, nugatory, and without significance. Appearances would nonetheless offer objects to our intuition (A90-1/B123).

This is clearly a scenario where the category of cause and effect lacks objective validity, something TD is supposed to show is false, and even counter to real possibility (hereafter 'counterpossible'). Conceptualists therefore read the above scenario - and the claim that intuition by no means requires concepts - as merely logically or epistemically possible, requiring a Transcendental Deduction to reveal as counterpossible.

This paper will analyze the $\S 13$ passage, to reveal counterpossible and factual elements in the passage. The main non-conceptualist claim - that intuitions can be had prior to and independently of concepts - is factual; the counterpossible element is the claim that we could have appearances for which the categories lack objective validity. The conjunction of these claims constitutes the central problem of TD: How, if intuitions can be had without concepts, can the categories be objectively valid of all possible appearances? However, conceptualists are right that standard non-conceptualist readings cannot adequately answer this question: on their reading the counterpossible element comes out as possible. Instead, the underappreciated upshot of the

Vernunft $K U=$ Kritik der Urteilskraft LD = Logik Dohna-Wundlacken LP = Logik Pölitz; $L W=$ Logik Wiener; $M D=$ Metaphysik Dohna $M K_{2}=$ Metaphysik $K_{2} ; M L_{1}=$ Metaphysik $L_{1} ; M L_{2}=$ Metaphysik $L_{2} ; M M r=$ Metaphysik Mrongovius $; M S=$ Metaphysik der Sitten $; M V i=$ Metaphysik Vigilantius $;$ Prol $=$ Prolegomena zu einer jeden künftigen Metaphysik, die als Wissenschaft wird auftreten können; $R=$ Reflexionen; ÜE = Über eine Entdeckung, nach der alle neue Kritik der reinen Vernunft durch eine altere entbehrlich gemacht werden soll. 
passage is that it best fits a strain of Kant interpretation, found perhaps most prominently in Longuenesse (1998) and (2005), that I label Non-Conceptual Intellectualism (NCI): A preconceptual activity of the understanding is required for intuition and ensures the objective validity of the categories.

NCI faces textual and systematic objections that help explain its hitherto limited uptake in the Kant literature. ${ }^{3}$ In brief: Textually, it is difficult to see exactly how the understanding, often defined as a faculty of concepts and judgment, can have a pre-conceptual employment. Systematically, it is unclear how a pre-conceptual use of the understanding ensures that the categories, as pure concepts, are applicable to appearances. While I will show that the textual worries can be assuaged, the systematic objection reveals a deeper difficulty inherent to the NCI reading of TD. I will analyze this difficulty and suggest that it in fact correctly expresses the difficulty inherent to Kant's strategy. Kant must not assume but prove that the pre-conceptual use of the understanding operates according to the "same function" (A79/B104) as expressed in the categories. He aims to do this, on the reading I propose, by showing that unless the same function is utilized in the pre-conceptual use, so that the categories are objectively valid for appearances, the pure intuitions of space and time are not possible. The objection reveals not so much a problem for NCI as the ambitious and interconnected nature of Kant's project. It thus leads us to better understand Kant's argumentative strategy in TD and in the following sections of the Transcendental Analytic.

\section{The Quarrel over $\$ 13$}

Most parties to the debate agree that A89-91/B122-3 in $§ 13$ prima facie suggests that intuitions can be given without having to be related to the understanding or to the categories. In short, the

\footnotetext{
${ }^{3}$ Typically, proponents of NCI hold that the pre-conceptual use of the understanding required for intuition consists in self-affection, the "synthetic influence of the understanding on the inner sense" (B154). This further specification is not required for Kantian NCI, but has solid textual support, and I generally assume it in the remainder of the article. However, nothing in this article hinges on this assumption, as I focus on problems relation specifically to a purported pre-conceptual use of the understanding, whether specified as self-affection or not. There are additional worries concerning the idea that self-affection (whether conceptual or pre-conceptual) is required for intuition, the view is defended against objections in Longuenesse (2005); Indregard (2017).
} 
claim is that intuition is prior to thought, such that one can have intuitions independently of, and even without having, concepts (including the categories). The following segments offer direct support:

Objects can indeed appear to us without necessarily having to be related to functions of the understanding (A89/B122).

Appearances can certainly be given in intuitions without functions of the understanding (A90/B122).

[I]ntuition by no means requires the functions of thinking (A91/B123).

The paragraph these quotes are drawn from is intended primarily to highlight a difficulty faced by TD. Clearly, the difficulty pertains to the relation of sensibility and its appearances to the understanding and its functions. "Appearances," objects of intuition, can according to these quotes be given without "functions of the understanding" or "functions of thinking." These functions are plausibly identified with concepts and conceptual judgment, as "thinking is cognition through concepts" (A69/B94), and "the functions of the understanding can (...) all be found together if one can exhaustively exhibit the functions of unity in judgment" (A69/B94). The passage thus appears to support non-conceptualism. ${ }^{4}$

The standard conceptualist response argues that the passage should be read counterpossibly; it serves a rhetorical function in setting up the problem that TD is supposed to solve. According to this retort the real upshot, contra the non-conceptualist reading, is not that intuitions in fact can be given without being "related to functions of the understanding"; the problem is rather that "it is not clear a priori" (A90/B122) if they can or cannot: "[T]hat [the objects of sensible intuition] must also accord with the conditions that the understanding requires for the synthetic unity of thinking is a conclusion that is not so easily seen" (A90/B122-3, my italics). The subsequent TD

\footnotetext{
${ }^{4}$ Non-conceptualists who appeal to this passage include Allais (2009: 387f.), (2016: 7-9); Hanna (2005: 259f.), (2016: 107); Tolley (2013: 125-6), (2016: 277).
} 
exhibits that which was difficult to see, namely that the logically possible scenario envisaged in $\S 13$ is not really possible. 5

This reply faces two problems. First, $\S 13$ is far from the only place in $K r V$ where Kant indicates the priority of intuition to conceptual thought:

That which, as representation, can precede any act of thinking something is intuition (B67).

That representation that can be given prior to all thinking is called intuition (B132).

The manifold for intuition must already be given prior to the synthesis of the understanding and independently of it (B145).

In the Aesthetic I ascribed this unity [of space and time] merely to sensibility, only in order to note that it precedes all concepts (B160-1n.).

Natural appearances are objects that are given to us independently of our concepts (A480/B508).

Similar passages are scattered throughout Kant's other writings. ${ }^{6}$ Since these passages are not drawn from the context of explaining the problem faced by TD, they render doubtful the textual basis for holding that pre-conceptual intuitions only seem to be really possible (but are not). ${ }^{7}$

Second, closer inspection of the passage reveals a subtler structure than generally noted, in a way that does not fit the conceptualist response. Kant uses two different verb moods: The indicative

\footnotetext{
5 "The not-so-easily-seen conclusion to be proved is that appearances cannot be given in intuition without being related to understanding via the categories" (Griffith 2012: 199). See also Bowman (2011: 422-3); Conant (2016: 101); Ginsborg (2008: 70-1); Gomes (2014: 6); Grüne (2011: 475f.); Land (2015: 31); Onof (2016: 209-10).

${ }^{6}$ See $K U, 5: 402 ;$ Anth, 7:142; FM, 20:324; EE, 20:227n., 20:245; N, 23:28; LP, 24:502; R220, 15:84, R4636, $17: 620$.

${ }^{7}$ Some commentators distinguish interpretations where concepts must be applied in judgment in order for intuition to arise, from interpretations which instead hold that a non-judgmental use of concepts is required (Grüne 2009; Land 2015). The passages noted above constitute prima facie evidence against both. Land (2015: 31-2) attempts to deal with two of the additional passages cited above (B132 and B145), but the overall strategy of holding that intuition requires non-judgmental use of concepts clearly faces an uphill textual battle.
} 
and the subjunctive mood. ${ }^{8}$ While the indicative mood is used when stating facts, the subjunctive mood is often used when making hypothetical and counterfactual statements. To see this, I will here reproduce a substantial stretch of the passage, divided into three distinct parts to be explicated below, with the parts written in the subjunctive mood italicized:

[1] The categories of the understanding, on the contrary, do not represent to us the conditions under which objects are given in intuition at all, hence objects can indeed appear to us without necessarily having to be related to the functions of the understanding, and therefore without the understanding containing their a priori conditions. Thus a difficulty is revealed here that we did not encounter in the field of sensibility, namely how subjective conditions of thinking should have objective validity, i.e., yield conditions of the possibility of all cognition of objects; for appearances can certainly be given in intuition without functions of the understanding. [2] I take, e.g., the concept of cause, which signifies a particular kind of synthesis, in which given something A something entirely different B is posited according to a rule. It is not clear a priori why appearances should contain anything of this sort (one cannot adduce experiences for the proof, for the objective validity of this a priori concept must be able to be demonstrated), and it is therefore a priori doubtful whether such a concept is not perhaps entirely empty and finds no object anywhere among the appearances. For that objects of sensible intuition must accord with the formal conditions of sensibility that lie in the mind a priori is clear from the fact that otherwise they would not be objects for us; but that they must also accord with the conditions that the understanding requires for the synthetic unity of thinking is a conclusion that is not so easily seen. [3] For appearances could after all be so constituted that the understanding would not find them in accord with the conditions of its unity, and everything would then lie in such confusion that, e.g., in the succession of appearances nothing would offer itself that would furnish a rule of synthesis and thus correspond to the concept of cause and effect, so that this concept would therefore be entirely empty, nugatory, and without significance. Appearances would nonetheless offer objects to our intuition, [1] for intuition by no means requires the functions of thinking (A89-91/B122-123, italics modified).

\footnotetext{
${ }^{8}$ Noted by Paton (1936/1976: vol I, 324n.), and Allais (2009: 387n13).
} 
I divide the passage into three distinct points based on the following distinctions: In [1] Kant is, seemingly at least, making statements of fact. In [2] he is raising worries or doubts. In [3] he is, again at least seemingly, speaking counterfactually. This division into different parts initially supports the non-conceptualist argument: The segments of the passage supporting nonconceptualism are drawn from [1], where Kant uses the indicative rather than subjunctive mood. This suggests taking them at face value. ${ }^{9}$ Notice the part of the sentence in [2] where Kant switches to the subjunctive mood: Since objects of sensibility in fact must accord with the "formal conditions of sensibility," Kant's description of how they would be if they did not, i.e., "otherwise" - that they would then not be objects for us -, is formulated in the subjunctive mood. If the entire quoted passage describes something that is ultimately counterpossible, it is puzzling why Kant uses the subjunctive mood only in [3] and this small part of [2].

The conceptualist must argue that the subjunctive mood of [3] reflects back onto [1]. The standard strategy at this point is to argue that non-conceptualism cannot make sense of the Transcendental Deduction - Kant's argument to justify the applicability of the categories to objects. ${ }^{10}$ If this is true, and were Kant's statements in [1] to express a commitment to nonconceptualism, TD would fail on Kant's own terms. In addition, of course, to the desirability of reading Kant so that his commitments do not contradict, this also appears to conflict with [3]: The categories' lack of objective validity that would follow from TD's failure is here depicted in the subjunctive mood. In other words, while conceptualism cannot read the statements in [1] at

\footnotetext{
${ }^{9}$ Gomes (2014: 6), following a Guyer \& Wood note in the $\mathrm{KrV}$ Cambridge Translation (1998: 725n17), points to a reflection supposedly describing a similarly counterfactual scenario in the indicative mood. I believe they misread the reflection in question, the relevant part of which goes as follows: "To be sure, something can appear to us without its ground appearing to us; but we cannot cognize it without presuming the cognition of a ground, because it would otherwise not be a cognition, i.e., objective representation" (R5221, 18:222-3). They read, I presume, the claim "something can appear to us without its ground appearing to us" as counterfactual. However, if one takes into account the distinction between appearance and object of experience, the passage is readily explainable as factual: Many appearances have grounds that do not themselves appear, because these grounds are objects of experience that are not, and perhaps cannot be, directly or consciously intuited by human sense organs (e.g. "magnetic matter" (A226/B273) or Newtonian "lamellae" ( $\ddot{U} E, 8: 205)$ ). We "presume $[\ldots]$ the cognition of a ground" because we presume that appearances have cognizable, i.e., empirical, causes among objects of experience.

${ }^{10}$ See Ginsborg (2008); Gomes (2010, 2014); Grüne (2009); Bowman (2011); Bauer (2012); Griffith (2012); Land (2015).
} 
face value, the claim advanced here is that non-conceptualists have the converse difficulty: They cannot read [3] counterpossibly, since for them the scenario expressed in [3] is a possibility. Given this choice, conceptualists may say, the entire passage is better read counterpossibly, since this reading is compatible with the success of TD. ${ }^{11}$ This overall strategy is fairly explicit e.g. in Gomes (2014), who states that "we are not forced to treat the possibility expressed at A90/B123 as metaphysical" (Gomes 2014: 6), within an overall interpretation according to which "nonconceptualism cannot provide an account of the Transcendental Deduction and thus ought to be rejected" (Gomes 2014: 1).

The point that we are not forced to treat the possibility as metaphysical is, I take it, at best only as strong as the argument that non-conceptualism cannot account for TD. ${ }^{12}$ Recently, however, non-conceptualist readings of TD have begun emerging. A common pattern can be identified among developed non-conceptualist readings: They tend to distinguish mere intuition, given prior to and independently of the understanding's activity, from other, more complex representations downstream from mere intuition - whether perception (Tolley 2013, forthcoming; McLear 2014: 780), the representation of intuition as intuition (Onof \& Schulting 2015) or as representations of objects (Allais 2015: ch. 11, 2016), representations of certain complex relations between intuitions (Golob 2016a, 2016b), cognition (Hanna 2005, 2011) or some other construal. These other, more complex kinds of representations require a contribution by the understanding and its categories, and can therefore be shown, by TD, to necessarily accord with the categories.

\footnotetext{
${ }^{11}$ Non-conceptualists might reply that the scenario expressed in [3] is in the subjunctive because the possibility is not actual; at least some of our appearances are in fact so constituted that their succession "correspond[s] to the concept of cause and effect." If Kant's starting point in the Deduction is a more robust conception of empirical cognition or experience, as some argue (e.g. Ameriks 1978; Allais 2015), the scenario is ipso facto counterfactual, although not necessarily counterpossible. Against this reading, even the possibility of the scenario is expressed in the subjunctive mood: In the first sentence, where Kant says "appearances could after all be so constituted that the understanding would not find them in accord with the conditions of its unity," the verb "could" is the subjunctive könnten in German. In addition, Kant claims in [2] that "one cannot adduce experiences for the proof, for the objective validity of this a priori concept must be able to be demonstrated." This seems to preclude appeal to mere contingent facts about appearances.

${ }^{12}$ Allais, more harshly, writes: "The conceptualist reading of this passage is simply not what Kant actually says" (Allais 2016: 8).
} 
This pattern reveals a fact about the $\S 13$ passage that has not yet been noted by participants in the debate: The passage is problematic for non-conceptualists even if any of the above interpretations convincingly account for TD, since all these interpretations leave open the possibility of the scenario in [3]. Crucially, Kant does not refer subjunctively to the possibility that objects of cognition or of experience might not accord with the categories, or that perception or conscious intuition might not accord with the categories - which would have bolstered the nonconceptualist readings. ${ }^{13}$ The scenario Kant envisages, in the subjunctive mood, is that appearance, i.e., the "undetermined object of an empirical intuition" (A20/B34), does not accord with the categories. Appearances preside at the most basic level, as objects of mere intuition, as opposed to objects of experience or phenomena - objects of intuition determined by the understanding (cf. ID, 2:394; A248-9). Even the possibility that these most basic sensory representations of objects do not accord with the categories is here characterized in the subjunctive mood. ${ }^{14}$

The mentioned non-conceptualist readings, on the other hand, are all committed to saying that appearances as such can fail to accord with the categories. Hanna (2011) and Allison (2012: 48) admit this explicitly. Schulting's affirmation of non-conceptualism "only in a trivial sense" similarly affirms the real possibility of the scenario in [3]: "[E]s gebe tatsächlich Anschauungen, welche (...) nicht einmal begrifflich verarbeitet werden können müssen (was der Konzeptualist grundsätzlich verneint)" (Schulting 2015: 580; see Schulting 2017: 230f.). He thinks conceptualist readers of Kant conflate "all appearances" with "all objects of possible experience" (2015: 573): Whereas the latter necessarily conform to the categories, the former might not.

Allais, though noticing the counterfactual part of the passage, denies that it is counterpossible: she states that "[Kant] is going to argue that appearances are so constituted that they are in

\footnotetext{
${ }^{13}$ It would also have matched his assertion a few pages later that "[categories] are related necessarily and a priori to objects of experience, since only by means of them can any object of experience be thought at all" (A93/B126, my italics).

14 This fits Kant's statements towards the end of the B-Deduction, that he will show the a priori applicability of the categories to "objects that can be given to us in intuition" (B151), or "whatever objects may come before our senses" (B159), so that "everything that may ever come before our senses must stand under the laws that arise $a$ priori from the understanding alone" (B160). "Everything that may ever come before our senses" presumably includes all possible appearances, which would indeed make the scenario in [3] counterpossible.
} 
accordance with the conditions of the unity of the understanding" (Allais 2016: 8). That she takes this to be a mere fact, not a necessary condition (of their being given in intuition), is indicated when she proceeds:

[Kant] says that he is going to show that objects presented to our experience do fall under the categories, but that this is not a condition of their being presented to our intuition, that their being presented to us in intuition does not depend on the categories, and that even if they did not fall under the categories they could still be presented to us in intuition (Allais 2016: 8).

She later claims that "[m]y nonconceptualist view of intuition does not require the actual or possible existence of what Hanna (2011) calls "rogue objects" - objects which do not fall under the categories" (Allais 2016: 24). However, it is difficult to see, on her view, anything preventing the possible existence of rogue appearances, i.e., undetermined objects of intuition which do not fall under the categories - she explicitly affirms that if appearances did not fall under the categories they "could still be presented to us in intuition." 15

Golob also defends the compatibility of TD with non-conceptualism. He states that "it is a direct consequence of my approach that the categories are not necessary for empirical intuition. Rather, they are necessary only for representing certain complex relations among such intuitions" (Golob 2016b: 44), and does not argue that objects of empirical intuitions must be such that they stand in the complex relations represented by the categories. Instead, he considers the fact that they do a "basic datum of human experience" that does not need justification (Golob 2016b: 49), and holds that "I do not think that the possibility of an alternative, non-categorical, mode of sensible experience should be problematic" (Golob 2016b: 50). In other words, his account - like those of Hanna, Allison, Allais, and Schulting - leave the scenario sketched in the subjunctive mood by Kant as a live possibility.

\footnotetext{
${ }^{15}$ One could hold that such objects, even if given in intuition, are not properly said to "exist," since existence is one of the categories. However, this rules out the possible existence of rogue objects only in a rather Pickwickian sense. In earlier work, Allais herself pointed out that Kant "considers (and rejects) the possibility that appearances could (könnten) be so constituted that the understanding would not find them in accord with the conditions of its unity" (Allais 2009: 387n., first emphasis mine). Her present reading of TD, however, seems incompatible with this point.
} 
My aim here is neither to prove the non-conceptualists wrong (in holding that objects can be given in mere intuition without conforming to the categories), nor to prove the conceptualists wrong (in holding that Kant's seemingly non-conceptualist claims at A89-90/B122-3 are counterpossible, since the Deduction is incompatible with non-conceptualism). My point is simply that the structure of the A89-90/B122-3 passage does not straightforwardly fit either view. While conceptualists cannot properly read [1] as indicative, non-conceptualists cannot properly read [3] as subjunctive. Note the final sentence from the quote, where Kant switches from the subjunctive mood to the indicative mood mid-sentence. The first part of the sentence states, in the subjunctive mood, that objects of intuition would still be given to us even if they were not "in accord with the conditions of [the understanding's] unity," i.e., in accord with the categories. The final part of the sentence claims, indicatively, that intuition does not require "functions of thinking." Both conceptualists and non-conceptualists, as these positions have been explicated here, must regard the change of mood as unmotivated - for both, the claims made in the two parts of the sentence stand or fall together.

If we take Kant's use of distinct moods in different parts of this passage seriously, we would instead expect that he is not either explicating a real possibility or putting forward a counterpossible scenario - he is doing both, in different parts of the passage. ${ }^{16}$ The upshot is the following two, distinct points: a) intuitions and appearances can be given prior to concepts and thinking; b) intuitions and appearances cannot be given without conforming to the categories (the scenario in which they fail to do so is counterpossible). The passage may then be read as setting up the challenge faced by TD: how to square these two points? The next section highlights an available answer that can read the indicative mood as factual and the subjunctive mood as counterpossible.

\section{Self-Affection and the Pre-Conceptual Use of the Understanding}

The reading I propose in fact constitutes a well-known, yet somewhat underappreciated view in the non-conceptualism debate: What I call Non-Conceptual Intellectualism (NCI) - that a pre-

\footnotetext{
${ }^{16}$ On this proposal, then, the section heading of Schulting's detailed discussion of this passage: "Der Passus in KrV, A89f./B122f.: Hypothese oder reale Möglichkeit?” (Schulting 2015: 568) sets up a false dichotomy.
} 
conceptual use of the understanding, namely the self-affection of our inner sense, is required for intuition. This view has been advocated by several interpreters; nonetheless, my impression is that it remains less than mainstream. ${ }^{17}$ One reason is that until recently, the non-conceptualism debate (as its name indicates) has mostly been framed as a debate about the purported role of concepts in intuition, rather than about the role of the understanding. ${ }^{18} \mathrm{~A}$ different reason, one that I hope to have weakened here, is a lack of appreciation of the arguments in favor of NCI. The previous section has shown how the standard positions in the debate cannot adequately account for both [1] and [3] in the A89-90/B122-3 passage. This gives an indirect argument for $\mathrm{NCI}$, since it can do so: NCI can accept the claims from [1], stated in the indicative mood, to the effect that intuition does not require concepts. It can nonetheless explain why [3] is counterpossible; the pre-conceptual use of the understanding is required for intuition and ensures that appearances are in accord with the categories. A final reason for NCI's relative lack of acceptance is that admitting a pre-conceptual use of the understanding seems problematic within the Kantian framework, for both systematic and textual reasons. After first explicating NCI's reading of TD in further detail, the remainder of this article will consider what I take to be the main reasons to be skeptical of any such non-conceptual use, and argue that none of these reasons are compelling.

Very briefly, NCI reads the Transcendental Deduction along something like the following lines (focusing on the B Deduction): In the so-called 'First Step', from $\S \S 15-20$, Kant argues that a categorial synthesis performed by the understanding is required for us to think about any given objects. In a 'Second Step', from $\S \S 22-26$, Kant argues that a pre-conceptual figurative synthesis, also performed by the understanding in the guise of the "productive imagination" (B152), is required for us to be given any objects in intuition: Since through the latter synthesis "space or

\footnotetext{
${ }^{17}$ Its most prominent defender is Longuenesse (1998), (2005). See also Waxman (1991), (2014); Banham (2005); Gomes (2010), (2014); Friedman (2012), and, for an early precursor to the view, Hegel (1802/1977: 74). McDowell should also be read as espousing a kind of NCI - see for example his claim that our sensible input, although shaped by conceptual capacities, nonetheless constitutes "a constraint from outside thinking and judging" (1996: 28). Most of his critics have missed this point, instead reading him as a straightforward conceptualist, though it is suggested by Speaks (2005: 390).

${ }^{18}$ McLear (2015), (2016) helpfully shifts the debate towards the question of the role of the understanding. I draw the term "Intellectualism" in NCI from his label for interpretations that require an activity of the understanding (whether conceptually or pre-conceptually) for intuition.
} 
time are first given as intuitions" (B161n.), any appearance given in space or time is similarly subject to the figurative synthesis. ${ }^{19}$ And although this figurative synthesis "precedes all concepts" (B161n.), it nonetheless ensures that objects of intuition accord with the categories. This figurative synthesis is thus the understanding's "first application (and at the same time the ground of all others)" (B152) to objects of intuition.

Since the figurative synthesis "precedes all concepts" it does not conflict with the passages in [1] from $\S 13$, analyzed above. ${ }^{20}$ But as a "condition under which all objects of our (human) intuition must necessarily stand, through which then the categories, as mere forms of thought, acquire objective validity, i.e., application to objects that can be given to us in intuition, but only as appearances" (B150-1), it nonetheless ensures that the scenario sketched in [3] is a counterpossibility. The figurative synthesis, then, simultaneously fulfils the seemingly conflicting demands of [1] and [3]. Accordingly, after advancing her reading of the role of selfaffection and the figurative synthesis in TD, Longuenesse points back to $§ 13$ :

[I]t is conceivable, said Kant at the beginning of the Deduction, that appearances be such that they cannot be reflected under any concept of causal relation, whereas it is impossible that an appearance be given that did not conform to the conditions of space and time. But now, if we accept the argument of section 26, the very fact that appearances are given in space and time is a sufficient ground for their being in conformity with the categories, even though it remains true that they are not given in a category (as 'in' an intuition) or even cognized under a category until the relevant operations (...) have generated such cognition. Nevertheless, since the space and time of the Transcendental Aesthetic are, as intuitions, products of synthesis speciosa or 'effects of understanding on sensibility,' the fact that appearances are given in them is sufficient warrant that they can be (...) subsumed under the categories (Longuenesse 1998: 226; see also 2005: 37).

\footnotetext{
${ }^{19}$ For this line of interpretation see further Longuenesse (1998: passim, esp. 212-213); Gomes (2010); Waxman (2014: ch. 14).

${ }^{20}$ This also fits Kant's characterization in the beginning of the Transcendental Aesthetic, that he will isolate the forms of sensibility by, among other things, abstracting from "everything which the understanding thinks through its concepts" (A22/B36). This presumably means abstracting from all conceptual use of the understanding, but not necessarily from its pre-conceptual use.
} 


\section{A Pre-Conceptual Aspect of the Faculty of Concepts?}

NCI remains a minority view, and faces both textual and systematic difficulties. ${ }^{21} \mathrm{I}$ begin by considering textual worries. Although the figurative synthesis is most often ascribed to the imagination, there is little doubt that Kant ultimately thought it something also characterizable as a "synthetic influence of the understanding on the inner sense" (B154, italics mine; see B150, $152,155,162 \mathrm{n}$.). But can it then take place without concepts, given that the understanding is characterized as a "faculty of concepts" and of judging by means of concepts (see e.g. A69/B94, A126, A160/B199; KU, 5:287; LW, 24:806), and that "the specific nature of our understanding consists in thinking everything discursively" (Prol, 4:333; see Winegar 2015)?

As proponents of NCI have noted, other important characterizations of the understanding in Kant are more amenable to a potentially pre-conceptual aspect: Waxman (2014: ch. 5) and Gomes (2010: 131-2), (2014: 13) argue that Kant takes the understanding to be more fundamentally a capacity for apperception (see e.g. B133-4n., A401; MMr, 29:889). Without here entering into the difficult issue of exactly how to understand the unity of apperception, we can note that when the final $\$ 26$ of TD argues that synthesis is required for the unity of intuition (B160-1, B160-1n.), it gestures back to the unity of apperception discussed in the beginning of TD. There, Kant already foreshadowed its application to intuition in a footnote (B136n.). And just as the figurative synthesis "precedes all concepts" (B161n.), the unity of apperception "precedes all concepts of combination a priori" (B131).

Longuenesse (1998), (2005) holds the understanding most fundamentally to be a "capacity to judge," expressed not just in overt judgments but also in the (pre-conceptual) effort to synthesize the sensible manifold in a way amenable to judgment. As a capacity to judge, the understanding differs from the more narrowly defined power of judgment (A130/B169f.), encompassing further

\footnotetext{
${ }^{21}$ Some problems raised for conceptualist views also apply to NCI, for instance that they must reject the possibility of (non-rational) animal intuitions. Since this is a general problem for intellectualist views and not specific to NCI (nor do I see NCI as providing any special resources for dealing with it, other than perhaps giving an interpretation of self-affection of our inner sense that suggests a specific difference between non-rational animal sensibility and human sensibility), I do not discuss it further here. For further on the possibility of a difference between human and animal sensibility, see Land (forthcoming).
} 
an effort towards judgment that is expressed in e.g. its effort to form concepts with which to judge (see e.g. $J L, 9: 93-5$ ). On this conception, it may also encompass an even more fundamental effort to synthesize the sensible manifold in a way that is teleologically geared towards making the sensibly given judgeable.

Waxman (1991), (2014) argues further that as a faculty of spontaneity, the understanding may find pre-conceptual expression. Spontaneity is a property of faculties or powers capable of selfdetermined activity, as opposed to receptive faculties that can only act in ways influenced by affection (see also Smit 2009; for the historical background to this conception see Dyck 2016). Such self-determination has no necessary connection with concepts, hence, Kant's claim that "the understanding, as spontaneity, can determine inner sense" (B150, my italics) may be intended to refer specifically to a self-determined yet pre-conceptual activity. Note that the three mentioned characterizations seem compatible: The pre-conceptual activity may be selfdetermined (i.e., spontaneous) by expressing the inner nature of the understanding as a capacity to judge, and it may do so by generating a synthetic unity of apperception in intuition.

Opponents may press the issue, however: Does not the synthetic activity in question nonetheless proceed according to rules, and are not concepts understood by Kant simply as rules of synthesis (see Grüne 2009; Winegar 2015; Schulting 2017: 313)? Further, although these other characterizations of the understanding may, at first glance, appear compatible with preconceptual activity, they do not provide positive evidence that there indeed is such an activity. If the only real evidence of pre-conceptual activity is a single mention of a synthesis which "precedes all concepts" (B161n.), it seems preferable to interpret that passage differently, rather than speculatively ascribing to the understanding an activity at odds with how Kant consistently characterizes the understanding elsewhere. ${ }^{22}$

NCI can muster further, positive evidence in favor of a pre- or non-discursive aspect of the understanding. One important piece of evidence is Kant's rejection of innate concepts: Kant holds that all concepts must be acquired through the understanding's activity ( $\ddot{U} E, 8: 221-3$; see ID, 2:395, 406; $\left.B r, 10: 82 ; M L_{1}, 28: 233 ; M L_{2}, 28: 542 ; M M r, 29: 763, M V i, 29: 949,952\right)$. On

\footnotetext{
${ }^{22}$ The B160-1n. passage is often taken to mean only that the synthesis precedes all concepts of space (see Allison 2004: 192-3, 2012: 41; Onof \& Schulting 2015).
} 
standard readings of what concepts are, the activity whereby the understanding acquires its first concept(s) must ipso facto be pre-conceptual ${ }^{23}$ : If concepts are best understood as a specific kind of ability or capacity (to synthesize, judge, and/or infer) (see e.g. Grüne 2009, Landy 2015), the activity whereby these abilities are first acquired cannot already require the same abilities; similarly, if concepts are instead understood as a specific kind of mental state, the activity whereby such states are first generated cannot presuppose the same states. ${ }^{24}$ As Kant reportedly says in a metaphysics lecture: "The understanding acquires concepts by its paying attention to its own use" $\left(M L_{2}, 28: 542\right)$ - the initial use, attended to in order for concepts to arise, cannot already involve concepts. ${ }^{25}$

Against this, Grüne (2009) argues extensively that what needs to be acquired is only clear concepts; obscure concepts, on the other hand, are innate (2009: ch. 4.2.2) and required for figurative/sensible synthesis. ${ }^{26}$ However, positive evidence for her proposal is thin; further, it fails to fit what Kant says about the original acquisition of the categories:

\footnotetext{
${ }^{23}$ Vanzo (2018) argues that Kant's denial of innatism should not be taken at face value - that Kant was, despite himself, an innatist with respect to the categories, in much the same vein as Leibniz. However, Vanzo still affirms that "the formation of the categories is the result of spontaneous mental acts" (2018: 21), acts that must presumably be prior to the concepts they will form.

${ }^{24}$ Bayne (2010) argues that Kantian concepts are best understood as both abilities (rules) and states (marks), i.e., as incorporating both aspects.

${ }^{25}$ One could object to this by arguing that the understanding's initial use and its initial concepts are co-instantiated and co-dependent - that there is no prior, pre-conceptual process of concept formation or acquisition. McDowell may be read in this way, e.g. when he says: "Why should the idea of experience as an actualization of conceptual capacities be threatened by the thought that some of the conceptual capacities in question are initiated in and by the very experiences in which they are actualized?" (2001: 182). As mentioned in a previous footnote, I think McDowell should be read as a proponent of NCI, which seems to fit his remarks about conceptual capacities in this passage; the point he makes seems to me less convincing if it concerns not just capacities but actual concepts. In any case, I doubt whether seeing the original acquisition of the categories as already involving the categories - not just as products but as something that already exists in the process whereby they are supposedly acquired - is plausible as a reading of Kant; insofar as "concepts of the understanding ( $\ldots)$ arise out of reflection" $(M M r, 29: 762)$, that which arises is most naturally read as postdating the process out of which it arises. I thank an anonymous referee for raising this issue.

${ }^{26}$ It is possible to read Longuenesse as holding a similar position: She states that concepts have "two aspects" (1998: 69), one of which are required for intuition, and claims further that "the concept must already be present in an
} 
The Critique admits absolutely no implanted or innate representations. One and all, whether they belong to intuition or to concepts of the understanding, it considers them as acquired. But there is also an original acquisition (as the teachers of natural right call it), and this of that which did not yet exist at all, and so did not belong to anything prior to this act ( $\ddot{U} E, 8: 221$, my italics).

Rather than a clarification of already possessed concepts, Kant here refers to an original acquisition "of that which did not yet exist at all." The appeal to original acquisition in natural right could have supported Grüne's proposal: Original acquisition refers to the acquisition of something that does not already belong to anyone, either because it already exists but have never before been owned (as e.g. an unoccupied piece of land, see $M S, 6: 258 \mathrm{f}$.), or because it has just been brought into existence (e.g. an author's entitlement to copyrights over her work). The original acquisition Kant has in mind is evidently of the latter, rather than the former kind; if he meant that the original acquisition consisted in making clear the categories, he would likely appeal to the former - consciousness would be claiming previously uncharted (obscure) parts of the terrain of the mind, obscure concepts, rather than something "which did not yet exist at all."27 Kant instead states that the acquisition of the categories "presupposes nothing innate save the subjective conditions of the spontaneity of thought (in conformity with the unity of apperception)" ( $\ddot{U} E, 8: 223)$. It is hard to see why Kant would have formulated himself in this way if he believed in innate obscure concepts - instead, his reference to spontaneity and to apperception supports

\footnotetext{
'undetermined' state, that is, in an intuitive state, or more precisely, as a still unreflected, 'obscure' rule for the synthesis of intuition" (1998: 118). My discussion of Longuenesse as an advocate of NCI in this article have disregarded this - in my view less central and convincing - aspect of her interpretation.

${ }^{27}$ A similar contrast is present in Kant's use of chemical-biological terminology: Kant refers to epigenesis as the generation of "a product, what before was not yet present, but now is generated for the first time" (MMr, 29:760; see $M D, 28: 684)$, as opposed to the generation of an educt, where what was there before has only taken on a new form (see Zammito 2003: 90-91). In these passages, Kant is arguing that we cannot think the soul qua substance as epigenetically produced (by parents), since we cannot conceive of the parents as having a "creative force" ( $M M r$, 29:761) to generate another substance; such creative force can only be conceived of in God. On the other hand, there is no similar problem with conceiving of the categories, concepts that are determinations rather than substances, as products generated by the power of understanding, as Zammito concludes: "The categories themselves should not be seen as preformed, but only as produced spontaneously by an innate capacity or power - a 'faculty' of mind, whose own origin was utterly inscrutable" (Zammito 2003: 92; see also Mensch 2013).
} 
the abovementioned idea that these aspects are amenable to a pre-conceptual reading. This is not to say that the understanding originally acquires the categories by means of figurative synthesis but if we must admit, in any case, a pre-conceptual use of the understanding in the original acquisition of the categories, the principled case against reading the figurative synthesis as preconceptual is considerably weakened.

Where does this leave the idea that concepts are the rules according to which the understanding operates (cf. A106, A141/B180; LDW, 24:693)? Presumably, the pre-conceptual use of the understanding does not operate without rules; "we cannot use our understanding, except according to certain rules" ( $J L, 9: 12)$, further, this would make it completely unclear how the applicability of the categories is secured by such use. After all, famously, the "same function that gives unity to the different representations in a judgment also gives unity to the mere synthesis of different representations in an intuition, which, expressed generally, is called the pure concept of the understanding" (A79/B104-5). NCI must hold that concepts are not simply the rules of the understanding as such; rather, concepts are representations of rules, functioning as a specific kind of rule for the understanding (perhaps a rule for making certain analytic judgments and inferences, as e.g. the concept "fox" entails "foxes are animals") but leaving open the possibility of rule-governed use of the understanding without concepts. The distinction between rules and representations of rules is present in Kant: "Everything in nature works in accordance with laws. Only a rational being has the capacity to act in accordance with the representation of laws" GMS, 4:412; cf. $J L, 9: 11$; see further Young 1988: 153-4). ${ }^{28}$ In the Second Analogy, Kant characterizes the concept of cause as the "representation of a rule determining the series of occurrences" (A196/B241). Since everything in nature (including the understanding) proceeds according to rules, we need not hold that rules the understanding follows necessarily are concepts (as opposed to being potentially represented by concepts): This would again threaten to make incomprehensible the original acquisition of categories, since when the understanding acquires its first concepts it must operate in accordance with rules, but ex hypothesi does not already possess conceptually expressed rules. Moreover, the understanding's activity in aesthetic judgment is said to follow rules without concepts: "The aesthetic power of judgment is thus a special faculty for judging things in accordance with a rule but not in accordance with concepts"

\footnotetext{
${ }^{28}$ Laws, on Kant's account, are necessary rules, see A113, A126, A216/B263.
} 
$\left(K U, 5: 194\right.$; see 5:216, 5:300, 5:307, 5:309). ${ }^{29}$ One can read the $\S 13$ passage analyzed above as also supporting this reading: Kant's subjunctive claim there is that "in the succession of appearances nothing would offer itself that would furnish a rule of synthesis and thus correspond [entspräche] to the concept of cause and effect" (A90/B123, my emphasis). The idea that the concept of cause and effect corresponds to that which furnishes a rule of synthesis seems more in line with conceiving concepts as representing such rules rather than being them. ${ }^{30}$

The "same function" passage, then, can be taken to mean that the understanding proceeds according to the same rules in figurative synthesis and intellectual synthesis - but only in the latter case proceeds according to representations of these rules, "expressed generally" as pure concepts. ${ }^{31}$ And when the $\$ 13$ passage states that intuitions can be given independently of "functions of thinking" and "functions of the understanding," NCI must take this to refer specifically to the use of these functions in thinking (rather than in sensible synthesis), performed by the understanding in a narrow sense (rather than the productive imagination). In other words, intuitions can be given without general representations of the fundamental rules according to which the understanding operates.

\section{Pre-Conceptual Use and Sameness of Function}

At this point, a systematic quandary arises concerning NCI's account of Kant's argumentative strategy. I have argued for ascribing a pre-conceptual activity to the understanding, nonetheless

${ }^{29}$ The point here is not that aesthetic judgment is made without using concepts at all; rather, the basis for the judgment lies not in a conceptual determination of the object, but in a rule-governed yet non-conceptual activity of the understanding in harmony (or, perhaps, disharmony) with the imagination. See further Heidemann (2016), who points out that "according to Kant aesthetic experience is cognition of a special kind that does not bear on conceptual activities" (2016: 118). Unfortunately, he conflates concepts and rules, and therefore claims further that "cognitive appreciation of the beautiful is not derived from rule-governed procedures of the mind" (2016: 118). As seen from the citations above, this is incorrect. Ginsborg (2015: part I) explores a way in which synthesis can be rule-governed without being conceptual.

${ }^{30}$ This evidence is far from clear, though, among other reasons because the verbs used are non-technical and somewhat vague, and also because the passage is phrased in the subjunctive: one could claim that since Kant later shows that concepts are rules of synthesis, the envisaged scenario is counterpossible.

${ }^{31}$ Similarly, the "rule is expressed in concepts a priori" (Bxvii; cf. A142/B181). 
operating according to the "same function" as expressed by the categories. But if the activity is pre-conceptual, how can we know that it operates according to the same function? How can we guarantee that it is a "synthesis of intuition achieved by the very same function that unites concepts in judgments" (Longuenesse 2005: 21)? One can reasonably worry that if the use of the understanding required for intuition is non-conceptual, the inference to the objective validity of the categories is a non-sequitur (see Senderowicz 2004). At least, NCI as hitherto explained has not made good on the need to argue for rather than simply presuppose the 'same function' point.

The worry is that the more one tries to legitimate the assumption of sameness of function by arguing that these functions exhaust the capabilities of the understanding, the more one ends up essentially conceiving of the understanding as a faculty of concepts and judgment (and not of a pre-conceptual use). After all, Kant maps these functions by explicating the forms of judgment in the Metaphysical Deduction. Conversely, the more one conceives of the understanding in the different ways suggested in section 4, e.g. as a faculty of spontaneity or apperception, in order to make the non-conceptual use of the understanding comprehensible, the more one makes the "same function" point something that requires further, independent argumentation. One might wonder if any explanatory headway has really been made: The initial problem arose due to the seeming independence of intuitions from pure concepts; now we struggle with the seeming independence of figurative synthesis from intellectual synthesis. As Schulting says: "Separating the various formally distinguishable elements of synthesis as an act of the understanding, both intellectual and figurative, invites an obvious explanatory regress, where a priori synthesis was supposed to provide the explanation stopper" (Schulting 2017: 26-7). Gomes addresses the worry in the following way:

[A]lthough the transcendental synthesis which makes possible our representation of time and space does not itself involve the categories, it has its origin in the same source as the categorial synthesis which takes place on the manifold of intuition given in space and time. Kant's thought seems to be that, because of this shared origin, appearances which are given in space and time thereby fall under the same synthetic unity of apperception as is responsible for synthesizing the manifold of intuition in accordance with the categories (Gomes 2010: 131-2). 
Unfortunately, this does not resolve the issue: If this origin, i.e., the understanding, is not exhaustively characterized in terms of conceptual judgment, how do we know that we have a full overview of its functions through its forms of judgment? ${ }^{32}$ If the understanding has two, on the face of it two quite different, ways of operating - one by synthesizing concepts in judgment, one by non-conceptually synthesizing a sensible manifold in intuition - how do we know that an exhaustive mapping of one of these ways of operating (in the forms of judgment) corresponds fully to the other way? ${ }^{33}$

Longuenesse suggests a teleological explanation at this point: The sensible synthesis is an "activity geared towards these forms [i.e. the logical forms of judgment]" (1998: 199): "[O]ne might speak of an actual conatus, a continual effort, to shape the representation of what affects us in order to exercise our judgment (...) the actualization of this conatus is the 'action of understanding on sensibility,' namely the synthesis speciosa, the figurative synthesis carried out by imagination" (1998: 208; see also Kitcher 2012: 34). If the understanding is fundamentally understood as a capacity to judge, its non-conceptual use can be understood as geared towards judgment - an "effort toward judgment" (Longuenesse 1998: 394-395) - and hence expressing the same functions. However, this teleological point cannot carry the argumentative burden of justifying the "same function" claim (nor is this necessarily Longuenesse's intention). To convince someone skeptical that the categories in fact must apply to all objects of intuition, teleological considerations about what our processing of sensibly given material is an effort

\footnotetext{
${ }^{32}$ We cannot say that sameness of function is simply what it means for the syntheses to have the same origin, so that the very possibility of the understanding's pre-conceptual use functioning differently is rendered absurd. First, this would arguably impose too narrow a straightjacket on what faculties are capable of (note, for instance, that the number of transcendental schemata is different from the number of forms of judgment, and that the understanding can analyze as well as synthesize). Second, it simply presupposes that our grasp of the understanding's discursive functions in judging gives a complete overview of its functions - a presupposition that can no longer be upheld when we claim that the understanding also has a different, pre-discursive and seemingly equally fundamental use. For in that case, it is possible that even if the understanding has just one set of functions by definition, its discursive use only displays a subset of these functions, and its pre-discursive use a different subset.

${ }^{33}$ This worry is exacerbated if one thinks (see Messina 2014) that the understanding has a use other than synthesis which is involved in the generation of space and time.
} 
towards will not fly ${ }^{34}$ : First, teleology is merely subjectively valid for Kant (cf. $\left.K U, 5: 396-397\right)$ and it therefore seems dubious to give it an essential role in establishing the objective validity of the categories. Second, Kant's own discussion of these issues does not appeal to teleology. The principal advantage of NCI against more typical forms of non-conceptualism, as discussed above, was its ability to provide an argument that the categories must be applicable not just to all objects of possible experience or cognition, but to all possible appearances in general, in line with the $\$ 13$ passage. To maintain this advantage, something more like a transcendental argument for sameness of function is needed.

Now NCI, as I have explicated it, does hold that the applicability of the categories is necessary for something that a skeptic about the objective validity of the categories is prone to accept, namely for having the intuitions of space and time (and thus also of things in space and time) this is how NCI reads the Second Part of TD. The systematic worry expressed here therefore clarifies something about the argumentative path NCI should take: It should argue that unless the same functions expressed by the categories also, pre-conceptually, apply in figurative synthesis, our pure intuitions of space and time would not be possible. How can this be done?

This paper can only suggest an outline of how the Transcendental Analytic meets the demand just stated. In my view, NCI should admit that the Transcendental Deduction alone does not accomplish this task: It may show that if experience is to be possible, space and time must be generated in accordance with a synthesis expressing the same function as the forms of judgment. ${ }^{35}$ However, this remains nothing more than a 'proof of concept,' in the following sense: It explains how the categories can be objectively valid - by corresponding to a figurative synthesis required for the pure intuitions of space and time - but it does not prove that this figurative synthesis must express the same functions as the categories, from premises that do not

\footnotetext{
${ }^{34}$ At least not without a lot of additional philosophical work: One may read Kern (2017) as pursuing a sophisticated defense of the teleological line with respect to the more general notion of our "capacity for knowledge (Erkenntnisfähigkeit)." Similarly, Goldman (2012) defends a regulative reading of the Kantian account of cognitive faculties. Evaluating their projects lies outside the scope of this article.

${ }^{35}$ Longuenesse reads TD as a regressive argument from experience, see (2006: 286), (2008: 512).
} 
already assume experience. ${ }^{36}$ The following parts of the Transcendental Analytic, however, can fulfil the promise sketched by TD: In the Schematism and the Analytic of Principles, Kant does not merely argue that and how the categories are limited and specified in their necessary applicability to objects of experience; he also shows how each of the sensibly specified categorial determinations, the schemata, are necessary in order for the pure intuitions of space and time to be possible. This can be seen clearly in the Schematism. There, Kant explains how the schemata for each of the categories necessitate certain properties of objects of experience. He also, however, explains how the same schemata simultaneously make time representable:

Now one sees from all this that the schema of each category contains and makes representable [vorstellig mache]: in the case of magnitude, the generation [Erzeugung] (synthesis) of time itself, in the successive apprehension of an object; in the case of the schema of quality, the synthesis of sensation (perception) with the representation of time, or the filling of time; in the case of the schema of relation, the relation of the perceptions among themselves to all time (i.e., in accordance with a rule of time-determination); finally, in the schema of modality and its categories, time itself, as the correlate of the determination of whether and how an object belongs to time. The schemata are therefore nothing but a priori time-determinations in accordance with rules, and these concern, according to the order of the categories, the time-series, the content of time, the order of time, and finally the sum total [nbegriff] of time in regard to all possible objects (A145/B184-5).

NCI can take Kant's statements here literally: Reference to how the schemata 'make representable' time, and to "the generation of time itself," can be understood as saying that the pure intuition of time is generated through these pre-conceptual uses of the understanding. The crux, stopping the threat of an explanatory regress, is that Kant presents the same pre-conceptual syntheses as responsible both for making the pure intuition of time possible, and for ensuring that all possible objects of intuition are in accordance with the categories, so that certain categorial Principles necessarily hold. Proving this is left to the Analytic of Principles, where Kant shows that specific necessary determinations of objects of experience in accordance with the categories

\footnotetext{
${ }^{36}$ See A233/B286, where Kant makes a clear distinction between a wider notion of a "deduction of the legitimacy" and a stricter notion of proof. For a reading of TD on which it is understood as an explanation rather than as a proof, see Edgar (2010).
} 
are entailed by the intuition of time (and space). To give some brief indication of how this reading would go, consider Kant's claim that if the First Analogy did not hold for objects of experience: "[T]he appearances would then be related to two different times, in which existence flowed side by side, which is absurd. For there is only one time, in which all different times must not be placed simultaneously but only one after another" (A188-9/B231-2). The implication here seems to be that since appearances must be given in one unique time, they must also accord with the First Analogy. Similarly, in the Second Analogy he states that "if it is a necessary law of our sensibility, thus a formal condition of all perceptions, that the preceding time necessarily determines the following time (in that I cannot arrive at the following time except by passing through the preceding one), then it is also an indispensable law of the empirical representation of the temporal series that the appearances of the past time determine every existence in the following time" (A199/B244). I take Kant's point here to be that if appearances were not given in accordance with the stated law of empirical representation of the temporal series (the law of causality), they could not be given in accordance with the formal condition - that the preceding time necessarily determines the following time. Thus, since appearances are necessarily given in accordance with the formal conditions of time (and space), they also necessarily accord with the principle.

Fully substantiating and defending the reading of the Transcendental Analytic just sketched is a major task, for a different occasion. However, it may be instructive to compare my proposal here with Waxman's interpretation. He holds that the synthesis speciosa which produces the pure intuitions of space and time is distinct from the time-determinations of transcendental schematism, insofar as the latter is "merely its extension from pure to empirical intuition, the effect of which is to relate the categories, via their determination of the manifold of pure-formal intuition, to the realities apprehended in empirical-material intuition corresponding to sensation" (Waxman 2014: 406). In other words, since the transcendental schemata concern categorial determinations of empirical objects in space and time, they must differ from the synthesis speciosa that concerns the categorial determination of space and time themselves:

Since formal intuition (...) expressly concerns only that in appearances which can be apprehended completely a priori, and so without regard to their matter (reality) corresponding to sensation, the categorial synthesis speciosa that confers objective unity 
of apperception in the manifold of formal intuition cannot be the same action as transcendental schematism but instead precedes it and makes it possible (Waxman 2014: 406).

Waxman (2014: ch. 15) therefore proceeds to present an interesting but admittedly speculative account - not found in Kant's own texts - of how figurative synthesis corresponding to the different categories might make time and space representable. ${ }^{37}$ The reading I propose avoids adding additional syntheses beyond those described by Kant, which can be considered a benefit both insofar as it requires less extrapolation from Kant's own claims, and insofar as it avoids regress worries that seem to arise with the addition of further syntheses. Instead, I draw a radically different conclusion from the two distinct roles Waxman identifies for pre-intellectual synthesis: Rather than seeing it as evidence for distinguishing the syntheses of the schemata from the synthesis speciosa, my interpretation reads Kant's argument as aimed at showing how the same synthesis fulfills both roles. Indeed, it reads the fulfillment of this task as the culmination of the Transcendental Analytic: Kant thereby proves the objective validity of the categories from grounds that he takes himself to have already established, namely the pure intuitions of space and time, thus showing the scenario sketched in the subjunctive mood in the $\$ 13$ as counterpossible. This reading has anti-skeptical force: Kant takes his arguments in the Transcendental Aesthetic to establish that space and time are pure intuitions and forms of intuition, and would therefore understand skeptics like Hume as forced to accept (after reading the Aesthetic) the reality of space and time thus understood, insofar as they admit temporal and spatial representations at all. Rather than a regressive argument from actual experience (cf. Ameriks 1978), we can then read the Deduction as commencing a progressive argument from the a priori conclusions concerning pure intuition in the Aesthetic to their necessary conditions. These necessary conditions turn out to be pre-conceptual a priori syntheses (cf. B160-1n.) that also ensure the applicability of the categories to objects of intuition. ${ }^{38}$

\footnotetext{
${ }^{37}$ Longuenesse similarly suggests that one must "fill in the intermediate steps in Kant's argument" by providing "a case-by-case explanation of the productive syntheses as they relate to the logicodiscursive forms for which they are produced, thus generating the schemata of the pure concepts of the understanding" (1998: 245).

${ }^{38}$ An anonymous referee poses the pertinent question of what becomes, on this reading, of the role of the First Step of the Deduction: If the whole weight of Kant's argument falls on showing that the applicability of the categories is a necessary condition for the pure intuitions of space and time, why does Kant begin the Deduction by a complex
} 
This sketch serves to at least signpost a route to answering the worry that NCI invites an “explanatory regress" (Schulting 2017: 27) by postulating two distinct acts of the understanding, without showing why these distinct acts must correspond: Kant stops this explanatory regress, not by appeal to a priori synthesis as such, but by proving that the same pre-conceptual a priori syntheses must be responsible both for ensuring that appearances are in accordance with the categories, and for ensuring that the pure intuitions of space and time are possible. As Senderowicz points out concerning Longuenesse's NCI: "[T]his supposition means that the representational features of space and time provide sufficient grounds for the claim that the categories must be applicable to whatever appears in space and time" (2004: 772). He considers this untenable, objecting that there is no sign of arguments for this in the Transcendental Aesthetic; however, if I am right showing this is the task not of the Aesthetic, but of the Analytic. The role of space and time in the Transcendental Analytic, then, is not simply to act as the terrain to which the understanding in its real use is restricted. Rather, their actuality functions as the key premise of the Transcendental Analytic, where their necessary conditions are carefully unfolded and argued for. On this sketch, NCI sets forward a research program for better understanding the Transcendental Analytic, its premises and its aims: Reading it as a sustained transcendental argument from the pure intuitions of space and time to the objective validity of the categories as the necessary condition of their possibility.

\section{Conclusion}

The overall aim of this article has been to elucidate a Kantian notion of a pre-conceptual use of the understanding required for intuition. I began by analyzing a famous passage in $\mathrm{Kr} V$ that has

argument showing that the categories are required for us to think an object of intuition in general? An adequate response falls outside my scope here, but a short indication: I take it that the First Step constitutes a "beginning of a deduction of the pure concepts of the understanding" (B144) because it elaborates the conceptual use of the understanding in relation to objects of intuition, i.e., the "unity that is added to the intuition through the understanding by means of the category" (B144). This is where our examination of the understanding's real use must start, since only its conceptual activity is immediately accessible to us (in judging), and only from that basis can we proceed to uncover a pre-conceptual use of the understanding that exhibits sameness of function, thereby showing "from the way in which the empirical intuition is given in sensibility that its unity can be none other than the one the category prescribes" (B144-145). 
been read as supporting the idea that intuition can arise fully independently of the understanding, on the one hand, and as setting forth an ultimately counterpossible scenario of having intuitions without concepts, on the other hand. I argued that the passage instead supports NCI, the view that pre-conceptual use of the understanding is required for intuition.

After briefly explaining how proponents of NCI have made sense of Kant's Transcendental Deduction, I considered objections to the account. Textually, one worry is that the understanding is characterized as a faculty of concepts. I argued that this characterization does not exhaust the understanding, and that Kant is, independently of NCI's reading of the Transcendental Deduction, committed to a pre-conceptual use of the understanding. This worry can therefore be put to rest. Systematically, NCI threatens to undermine the justification for ascribing objective validity to the categories - if the use of the understanding required for intuition is pre-conceptual, how can it guarantee the applicability of certain concepts? Here, I argued that taking this objection seriously suggests a research program for NCI that has not hitherto been fully executed, namely, reading the Transcendental Analytic as a sustained transcendental argument, from the intuitions of space and time to their necessary conditions of possibility: pre-conceptual a priori syntheses that also make a priori principles concerning the objects of intuition necessary. While I gave, briefly, some reasons to believe that this research program might prove successful, it remains open to objections and potential failure. My aim here has been to elucidate the status of NCI, as a way of interpreting Kant's strategy in the Transcendental Deduction and beyond. I hope to have at least made the case that it is a promising approach, meriting further research.

\section{Bibliography:}

Allais, Lucy. (2009) "Kant, Non-Conceptual Content, and the Representation of Space." Journal of the History of Philosophy, 47.3, 383-413.

(2015) Manifest Reality: Kant's Idealism and His Realism. Oxford: Oxford University Press. 
(2016) "Conceptualism and Nonconceptualism in Kant: A Survey of the Recent

Debate.” In Kantian Nonconceptualism, ed. Dennis Schulting. London: Palgrave Macmillan, 126.

Allison, Henry E. (2004) Kant's Transcendental Idealism. Revised and enlarged edition. New Haven and London: Yale University Press.

(2012) Essays on Kant. Oxford: Oxford University Press.

Ameriks, Karl. (1978) “Kant's Transcendental Deduction as a Regressive Argument." Kantstudien, 69, 273-87.

Banham, Gary. (2005) Kant's Transcendental Imagination. London: Palgrave Macmillan.

Bauer, Nathan. (2012) “A Peculiar Intuition: Kant's Conceptualist Account of Perception." Inquiry, 55.3, 215-237.

Bayne, Steven M. (2010) “Marks, Images, and Rules: Concepts and Transcendental Idealism.” In Kant's Idealism: New Interpretations of a Controversial Doctrine, ed. Dennis Schulting and Jacob Verburgt. Berlin: Springer, 127-42.

Bowman, Brady. (2011) “A Conceptualist Reply to Hanna’s Kantian Non-Conceptualism.” International Journal of Philosophical Studies, 19.3, 417-446.

Conant, James. (2016) “Why Kant Is Not a Kantian.” Philosophical Topics, 44.1, 75-125.

Dyck, Corey W. (2016) "Spontaneity Before the Critical Turn: The Spontaneity of the Mind in Crusius, the Pre-Critical Kant, and Tetens." Journal of the History of Philosophy, 54.4, 625-48.

Edgar, Scott. (2010) "The Explanatory Structure of the Transcendental Deduction and a Cognitive Interpretation of the First Critique." Canadian Journal of Philosophy, 40.2, 285-314.

Friedman, Michael. (2012) “Kant on Geometry and Spatial Intuition.” Synthese, 186.1, 231-55.

Ginsborg, Hannah. (2008) “Was Kant a Nonconceptualist?” Philosophical Studies, 137.1, 65-77. (2015) The Normativity of Nature: Essays on Kant's Critique of Judgement. Oxford: Oxford University Press. 
Goldman, Avery. (2012) Kant and the Subject of Critique: On the Regulative Role of the Psychological Idea. Bloomington, IN: Indiana University Press.

Golob, Sacha. (2016a) "Kant as Both Conceptualist and Nonconceptualist.” Kantian Review, $21.3,367-91$.

(2016b) "Why the Transcendental Deduction Is Compatible with Nonconceptualism." In Kantian Nonconceptualism, ed. Dennis Schulting. London: Palgrave Macmillan, 27-52.

Gomes, Anil. (2010) “Is Kant's Transcendental Deduction of the Categories Fit for Purpose?" Kantian Review, 15.2, 118-137.

(2014) "Kant on Perception: Naive Realism, Non-Conceptualism, and the BDeduction.” Philosophical Quarterly, 64, 1-19.

(2017) “Naïve Realism in Kantian Phrase.” Mind, 126.502, 529-578.

Griffith, Aaron M. (2012) "Perception and the Categories: A Conceptualist Reading of Kant's Critique of Pure Reason." European Journal of Philosophy, 20.2, 193-222.

Grüne, Stefanie. (2009) Blinde Anschauung. Die Rolle von Begriffen in Kants Theorie sinnlicher Synthesis. Frankfurt am Main: Vittorio Klostermann.

(2011) “Is There a Gap in Kant's B Deduction?” International Journal of Philosophical Studies, 19.3, 465-90.

Hanna, Robert. (2005) “Kant and Nonconceptual Content." European Journal of Philosophy, 13.2, 247-290.

(2011) 'Kant's Non-Conceptualism, Rogue Objects, and The Gap in the B Deduction.” International Journal of Philosophical Studies, 19.3, 399-415.

(2016) "Directions in Space, Nonconceptual Form and the Foundations of Transcendental Idealism." In Kantian Nonconceptualism, ed. Dennis Schulting. London: Palgrave Macmillan, 99-116. 
Hegel, Georg Wilhelm Friedrich. (1802/1977) Faith and Knowledge. An English Translation of G. W. F. Hegel's Glauben und Wissen. Translated and edited by Walter Cerf and Henry Silton Harris. Albany: SUNY Press.

Heidemann, Dietmar. (2016) “Kant's Aesthetic Nonconceptualism.” In Kantian Nonconceptualism, ed. Dennis Schulting. London: Palgrave Macmillan, 117-44.

Indregard, Jonas Jervell. (2017) "Self-Affection and Pure Intuition in Kant." Australasian Journal of Philosophy, 95.4, 627-643.

Kant, Immanuel. (1900-) Kants gesammelte Schriften. Edited by the Akademie der Wissenschaften. Berlin: Walter de Gruyter. (1992-) The Cambridge Edition of the Works of Immanuel Kant. Edited by Paul Guyer and Allen Wood. Cambridge: Cambridge University Press.

Kern, Andrea. (2017) Sources of Knowledge: On the Concept of a Rational Capacity for Knowledge. Translated by Daniel Smyth. Cambridge, MA: Harvard University Press.

Kitcher, Patricia. (2012) "Kant's Unconscious 'Given"”. In Kant's Philosophy of the Unconscious, eds. Piero Giordanetti, Riccardo Pozzi and Marco Sgarbi. Berlin: De Gruyter, 5-36. Land, Thomas. (2015) "Nonconceptualist Readings of Kant and the Transcendental Deduction." Kantian Review, 20.1, 25-51.

(forthcoming) "Conceptualism and the Objection from Animals." In Akten des 12. Internationalen Kant-Kongresses, eds. Violetta L. Waibel and Margit Ruffing. Berlin: De Gruyter.

Landy, David. (2015) Kant's Inferentialism: The Case against Hume. New York: Routledge.

Longuenesse, Béatrice. (1998) Kant and the Capacity to Judge. Sensibility and Discursivity in the Transcendental Analytic of the Critique of Pure Reason. Translated by Charles T. Wolfe. Princeton: Princeton University Press.

(2005) Kant on the Human Standpoint. Cambridge: Cambridge University Press. 
(2006) "Self-Consciousness and Consciousness of One's Own Body: Variations on a Kantian Theme.” Philosophical Topics, 34.1-2, 283-309.

(2008) "Cassam and Kant on 'How Possible' Questions and Categorial Thinking." Philosophy and Phenomenological Research, 77.2, 510-7.

McDowell, John. (1996) Mind and World. With a New Introduction. Cambridge, MA: Harvard University Press.

(2001) "Comment on Richard Schantz, 'The Given Regained"” Philosophy and Phenomenological Research, 62.1, 181-184.

McLear, Colin. (2014) “The Kantian (Non)-Conceptualism Debate.” Philosophy Compass, 9, 769-790.

(2015) "Two Kinds of Unity in the Critique of Pure Reason." Journal of the History of Philosophy, 53.1, 79-110.

(2016) “Getting Acquainted with Kant." In Kantian Nonconceptualism, ed. Dennis Schulting. London: Palgrave Macmillan, 171-97.

Mensch, Jennifer. (2013) Kant's Organicism: Epigenesis and the Development of Kant's Critical Philosophy. Chicago: University of Chicago Press.

Messina, James. (2014) "Kant on the Unity of Space and the Synthetic Unity of Apperception." Kant-studien, 105.1, 5-40.

Onof, Christian. (2016) "Is There Room for Nonconceptual Content in Kant's Critial Philosophy?" In Kantian Nonconceptualism, ed. Dennis Schulting. London: Palgrave Macmillan, 199-226.

Onof, Christian and Schulting, Dennis. (2015) "Space as Form of Intuition and as Formal Intuition. On the Note to B160 in Kant's Critique of Pure Reason." Philosophical Review, 124.1, $1-58$.

Paton, Herbert James. (1936/1976) Kant's Metaphysic of Experience: A Commentary on the First Half of the Kritik der reinen Vernunft. 2 vols. London: Humanities Press. 
Pendlebury, Michael. (1995) "Making Sense of Kant's Schematism." Philosophy and Phenomenological Research, 55.4, 777-97.

Schmitz, Friederike. (2015) "On Kant's Conception of Inner Sense: Self-Affection by the Understanding.” European Journal of Philosophy, 23.4, 1044-63.

Schulting, Dennis. (2015) „Probleme des 'kantianischen' Nonkonzeptualismus im Hinblick auf die B-Deduktion.“ Kant-studien, 106.4, 561-80. (2017) Kant's Radical Subjectivism. Basingstoke: Palgrave Macmillan.

Senderowicz, Yaron M. (2004) "Figurative Synthesis and a Priori Knowledge." The Review of Metaphysics, 57.4, 755-85.

Smit, Houston. (2009) "Kant on Apriority and the Spontaneity of Cognition." In Metaphysics and the Good: Themes from the Philosophy of Robert Merrihew Adams, ed. Samuel Newlands and Larry M. Jorgensen. Oxford: Oxford University Press, 188-251.

Speaks, Jeff. (2005) “Is There a Problem about Nonconceptual Content?” Philosophical Review, 114.3, 359-98.

Tolley, Clinton. (2013) “The Non-Conceptuality of the Content of Intuitions: A New Approach.” Kantian Review, 18.1, 107-36.

(2016) "The Difference between Original, Metaphysical and Geometrical Representations of Space." In Kantian Nonconceptualism, ed. Dennis Schulting. London: Palgrave Macmillan, 257-86.

(forthcoming) "The Meaning of 'Perception' in Kant and His Historical Context." In Natur und Freiheit: Akten des XII. Internationalen Kant-Kongresses 2015.

Vanzo, Alberto. (2018) "Leibniz on Innate Ideas and Kant on the Origin of the Categories." Archiv für Geschichte der Philosophie, 100.1, 19-45.

Waxman, Wayne. (1991) Kant's Model of the Mind. Oxford: Oxford University Press. (2014) Kant's Anatomy of the Intelligent Mind. Oxford: Oxford University Press. 
Winegar, Reed. (2015) "Review of Kant's Anatomy of the Intelligent Mind by Wayne Waxman." Notre Dame Philosophical Reviews, published 2015.11.01. http://ndpr.nd.edu/news/kant-sanatomy-of-the-intelligent-mind/

Young, J. Michael. (1988) “Kant’s View of Imagination.” Kant-studien, 79, 140-64.

Zammito, John. (2003) “'This Inscrutable Principle of an Original Organization': Epigenesis and 'Looseness of Fit' in Kant's Philosophy of Science." Studies in History and Philosophy of Science, 34, 73-109. 